\title{
Musculoskeletal symptoms among workers in the commercial fishing fleet of Norway
}

\author{
Mariann Sandsund ${ }^{1}$, Anita Øren ${ }^{1}$, Trine Thorvaldsen ${ }^{2}$, Ingunn Holmen ${ }^{2}$, \\ Signe Sønvisen ${ }^{2}$, Cecilie Thon Heidelberg ${ }^{3}$, Lisbeth Aasmoe ${ }^{3}$ \\ ${ }^{1}$ SINTEF Digital, Trondheim, Norway \\ ${ }^{2}$ SINTEF Ocean, Trondheim, Norway \\ ${ }^{3}$ University Hospital of North Norway, Department of Occupational and Environmental Medicine/ \\ /The Arctic University of Norway, Department of Medical Biology, Tromsø, Norway
}

\begin{abstract}
Background: Fishers exposed to unfavourable environmental conditions may suffer negative health effects. This study aimed to identify musculoskeletal symptoms in professional fishers in Norway using data from several sources; register data, telephone survey and questionnaire.

Materials and methods: Professional fishers $(n=25,971)$ registered in the period 2008-2013 were selected by Statistics Norway (SSB). An age- and gender-matched control population ( $n=77,913)$ was also selected. Outpatient consultation and hospitalisation data were received from the Norwegian Patient Registry (NPR). To obtain information about self-reported symptoms, 832 registered fishers on board Norwegian fishing vessels were interviewed by telephone, and a questionnaire was distributed to the crews of 5 trawlers $(n=153)$. Results: Data from NPR showed that fishers, compared to the control population, suffered significantly more acute incidents related to musculoskeletal disorders (5.4\% vs. $4.8 \%$, respectively), injuries to arms (11.3\% vs. $9.8 \%$ ), feet ( $8.4 \%$ vs. $8 \%$ ), and back ( $0.9 \%$ vs. $0.7 \%$ ). In the telephone survey, $61 \%$ and $43 \%$ reported that they performed monotonous work operations and heavy lifting often or very often, respectively. Thirty-three per cent had experienced pain in neck/shoulders/arms often or very often during the previous 12 months, and $93 \%$ believed this was fully or partly due to their work situation. The questionnaire among trawler crew members showed that $57 \%$ and $60 \%$ had experienced stiffness and/or pain in neck/ /shoulders and lower back/small of the back respectively during the previous 12 months.

Conclusions: Data from the register study, telephone survey and questionnaire all confirmed that musculoskeletal problems are common among fishers and related to their work situation. However, $77 \%$ of the fishers in all vessel groups and on board the 5 trawlers reported their own health as being very good or good.

(Int Marit Health 2019; 70, 2: 100-106)

Key words: fishing, musculoskeletal disorders, registries, telephone survey, questionnaire, occupational health

\section{INTRODUCTION}

The fishing fleet in Norway employs people on board different types of vessel, ranging from owner-operated coastal vessels to large deep-sea factory trawlers with up to $30 \mathrm{crew}$ members, which mostly operate in the Barents and Norwegian Seas [1]. Workers in the fishing fleet may be exposed to a variety of unfavourable conditions such as cold, changing temperatures, repetitive work tasks, heavy workloads,

noise, inconvenient working hours, long work days and high level of stress. As a result, they are likely to be negatively affected in terms of health and work performance [2-4]. Several ergonomic stressors at all stages of fishing dictated by some unpredictable factors such as weather conditions, as well as type of vessel, gear in use, crew size and level of experience are identified [5]. A Danish study concluded that despite positive developments in the physical work
\end{abstract}

Mariann Sandsund, Senior Scientist, PhD, SINTEF Digital, Department of Health Research, 7465 Trondheim, Norway, tel: +47 982 45138, e-mail: mariann.sandsund@sintef.no 
environment, fishers still experience heavy workloads and suboptimal ergonomic conditions [6].

Musculoskeletal disorders (MSD) are reported to be the most common cause of sick leave, directly affecting individuals and indirectly, health care and social security systems [7-10]. A recent study of Norwegian fishers found several health challenges (including MSD) related to exposures in the work environment such as repetitive and monotonous work operations and heavy lifting [4]. The same study also found that about $50 \%$ of fishers' doctor-certified sick leave in 2013 was due to MSD [11]. Studies from other countries show that there is a connection between fishers' work and MSD. For instance, vessel movement has been pointed to as a cause of musculoskeletal stress for fishers, which is aggravated by lifting or carrying weight [12]. Similarly, musculoskeletal symptoms were found in a sample population of American fishers, especially in the lower back and hands or wrists, and were a common reason for impaired work performance [5]. Another American study identified several occupational risks that might contribute to cumulative MSD, such as repetitive work, forceful exertions, awkward or static postures, low temperatures, vibration and muscle strain caused by the need to continually maintain balance [13]. Studies from other occupations show that cold, wet and windy conditions also negatively affect work performance, comfort, and that cold-related health problems (such as rhinitis, muscle pain, back pain, white fingers/Raynaud's syndrome, difficulties in breathing), are likely to occur more frequently at low ambient temperatures than in warm environments [14-19]. Low-intensity repetitive work in cold $\left(5^{\circ} \mathrm{C}\right)$ environments may negatively affect muscle function and cause fatigue [20], which may lead to overuse injuries and MSD in the long run [21]. Research in onshore seafood production plants found that the low temperatures needed to ensure high-quality fish products can increase the risk of symptoms in muscles, skin and airways $[22,23]$. Studies from Iceland made similar findings on the prevalence of musculoskeletal symptoms, particularly among workers performing repetitive and monotonous tasks [24]. These findings are thought also to be relevant to trawlers with on-board processing of fish. Lipscomb et al. (2004) [5] pointed out that reducing ergonomic exposures among commercial fishers is important.

During the past few years analyses show a decline or stagnation in personal accidents in the Nordic fishing fleet [25]. The focus for research and regulation in the Norwegian fishing fleet has been acute injuries and fatalities [26, 27] and most of the literature has also focused on this aspect [28]. However, there is still a lack of research-based knowledge regarding interactions between work, the work environment and occupational health among Norwegian fishers. This gap in our knowledge also includes several musculoskeletal disease subgroups.
Our aim was to study symptoms of musculoskeletal disease among occupational fishers in the Norwegian fishing fleet using three different research methods. We hypothesised that use of official sickness absence register data, a telephone survey and a questionnaire would demonstrate that MSD were the main cause of sickness absence, and that exposure to the work environment on board fishing vessels results in a higher incidence of musculoskeletal symptoms.

\section{MATERIALS AND METHODS}

We combined quantitative (registries, questionnaire study) and qualitative (telephone survey) methods (methods triangulation) [29]. The three methods used covered different sample populations of occupational fishers. The register data are based on doctor certified sickness absence due to MSD in more than 25,000 fishers in the period 2008-2013. Respondents in the telephone survey were identified and selected in 2014 through Norway's official register of fishers $(n=832)$, while the questionnaire $(n=153)$ included crew members on five trawlers operating in the Barents Sea in 2013-2015.

\section{REGISTRIES}

A sample of fishers ( $n=25,971)$ was drawn by Statistics Norway (SSB) based on the Standard Industrial Classification (SIC2002/2007) and the Standard Classification of Occupations (ISCO-88/08) for fishers between 2008 and 2013. An age- and gender-matched control population ( $n=77,913$ ) was drawn for comparative analysis. Sick leave and diagnosis data were obtained from the Norwegian Labour and Welfare Administration (NAV), while hospitalisation data (inpatient and outpatient data) were obtained from the Norwegian Patient Registry (NPR). Diagnoses leading to sick-leave were categorised in accordance with the International Classification of Primary Care, second edition (ICPC-2), while the International Classification of Diseases, tenth edition (ICD-10), is the standard classification tool for hospitalisation data. The data from SSB or NAV were coupled to data from the NPR. SSB forwarded the Social Security number of the population directly to the NPR from where the researchers received an anonymised data file.

\section{TELEPHONE SURVEY}

A total of 1,000 registered fishers on board Norwegian fishing vessels participated in a telephone survey in 2014 . Respondents were identified through the official fisher registry in Norway, and 832 were active fishers at the time of the survey. The mean age of the respondents was 50 years old and $2 \%$ were women. The same study population as reported by Sønvisen et al. (2017) [4] was used. 
The telephone survey comprised 99 questions, a few of which concerned musculoskeletal symptoms. The questions covered general information about vessel category and length, fishing operations, work experience, work tasks, organisation of work, sick leave and various symptoms, as well as subjective perceptions regarding work environment and health and health-promoting factors. The questionnaire was drawn up by the research team, and a professional polling agency conducted the survey by telephone.

The following questions covered musculoskeletal symptoms: In the previous 12 months, to what degree have you experienced pain in the 1) neck/shoulders/arms, 2) back and 3) knees/hips? The subjects were asked to rate each item on a 5 -point scale ranging from a very small to very large degree. Individuals who answered a "large degree" or a "very large degree" were asked if they thought their symptoms were related to their work situation. Questions related to the physical work situation included factors such as repetitive and monotonous work operations, heavy lifting, lifting with the upper body twisted or bent and working with hands at or above shoulder height. The subjects were asked to rate each item on a 5-point scale ranging from very seldom/never to very often. Furthermore, the fishers were asked to rate their self-perceived health on a 5-point scale ranging from very bad to very good.

\section{QUESTIONNAIRE STUDY}

Field studies were carried out on board 5 factory trawlers in the Norwegian and Barents Sea [30, 31]. Before fishing commenced, 153 crew members were recruited to participate in the questionnaire study. The mean age of the participants was 40.1 years and $5.2 \%$ were women. One hundred and two (67\%) crew members were directly engaged in fishing and were fishers, netman, factory manager, foreman, apprentice, while 51 were skipper, mate, chief engineer, engineer, steward or catering personnel.

The 67-item questionnaire covered questions about demography, working conditions, health and work-related health. The following questions were asked: In the previous 12 months, have you experienced stiffness and/or pain from: 1) neck/shoulders, 2) elbow/under arm/hand, 3) lower part of the back, 4) upper part of the back 5) hips/ /thigh/feet? The fishermen were also asked to rate their self-perceived health.

All methods were approved by the Data Protection Official for Research, Norwegian Centre for Research Data or the Regional Research Ethics Committee in Medicine, Norway.

\section{DATA ANALYSES}

Statistical analyses used the SPSS statistical package. The outcome variables from the telephone survey and the questionnaire study were determined using descriptive statistics (frequency analyses). Data from the registries were analysed by $\chi^{2}$ or Student's t-test, and the significance levels were set to $p<0.01$ or 0.05 , respectively.

\section{RESULTS}

\section{REGISTRIES}

Analysis of sick-leave provided by NAV showed that fishers had a significantly higher percentage of sickness absence (5.2\%) than the age- and gender-matched control group (4.6\%) in 2013 [11]. Moreover, MSD were the main cause of sickness absence among fishers (50\%), which was significantly higher (t-test, $\mathrm{p}<0.05$ ) than in the age- and gender-matched control group (45\%).

Looking into the ICPC-2 MSD codes in more detail, the fishers were overrepresented compared to the controls in the codes for muscle pain, hand/finger, ankle, muscle symptoms/complaints not otherwise specified (NOS), leg/thigh and jaw, sprained/strained ankle, musculoskeletal injury NOS and hand/foot bone fracture.

Analysis of hospitalisation and outpatient consultation data from the NPR for the period 2008-2013 (average) showed that fishers, compared to the control population, suffered significantly more acute incidents due to musculoskeletal diseases (5.4\% vs. $4.8 \%$, respectively), and injuries in arm (11.3\% vs. $9.8 \%)$, foot (8.4\% vs. $8 \%$ ) and back $(0.9 \%$ vs. $0.7 \%)$.

\section{TELEPHONE SURVEY}

In the telephone survey ( $n=832), 61 \%$ of the respondents reported that they performed monotonous work operations often or very often, while $43 \%$ and $42 \%$ reported heavy lifting and lifting with the upper body twisted or bent, respectively (Fig. 1). Fishers who reported frequent or very frequent exposure to humid environments, strong winds and cold were $68 \%, 37 \%$ and $40 \%$, respectively. Thirteen per cent reported that they felt cold at work often or very often, while $25 \%$ occasionally reported this (Fig. 1).

Thirty-three per cent had experienced pain in the neck/ /shoulders/arms to a considerable or very considerable degree during the previous 12 months, while $19 \%$ and 15\% had experienced pain in the back and knees/hips, respectively (Fig. 2). Of those who reported health complaints, $82-93 \%$ believed these pains were completely or partly due to their work situation. In terms of operating modes, differences were seen between trawl, autoline and coastal vessels. Pain in the neck/shoulders/arms was reported higher among fishers on coastal vessels (42\%) compared to trawl (20\%) whereas pain in the knees/hips were higher in trawl (23\%) than in coastal fishing (16\%). Expressed as relative risk (RR), fishers in the coastal fishing fleet have 


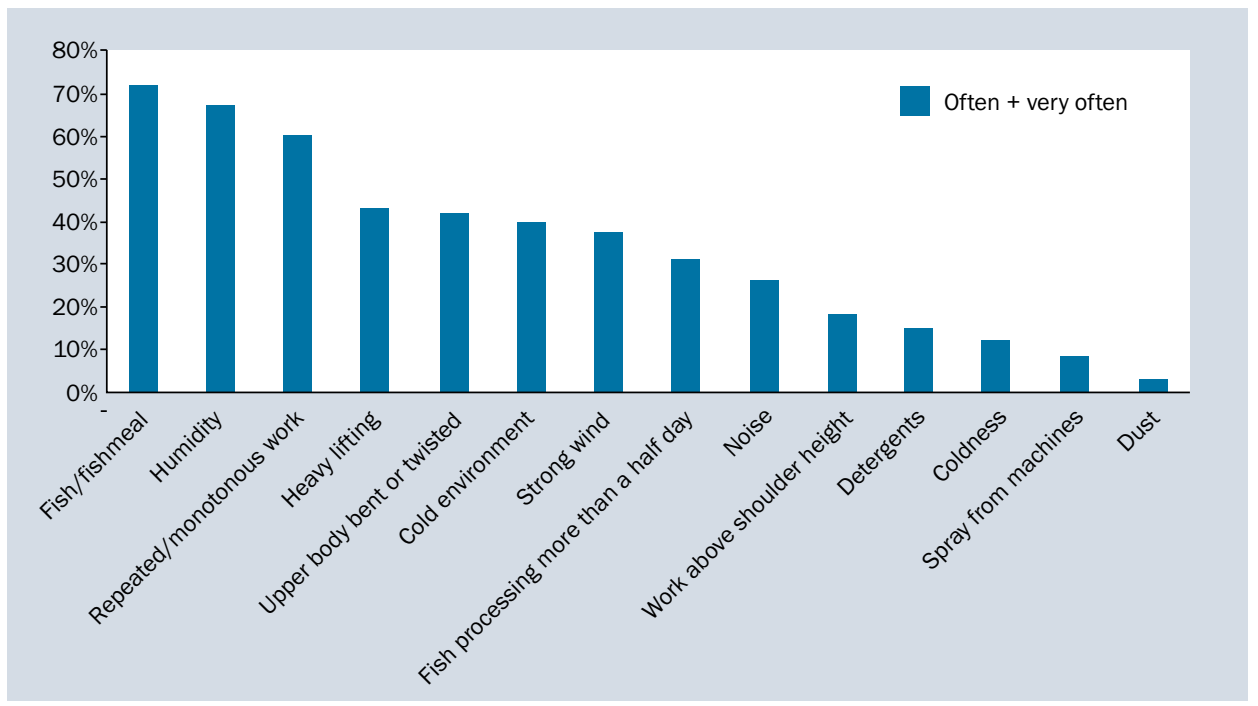

Figure 1. Self-reported exposure in the fishers' work environment $(n=832)$

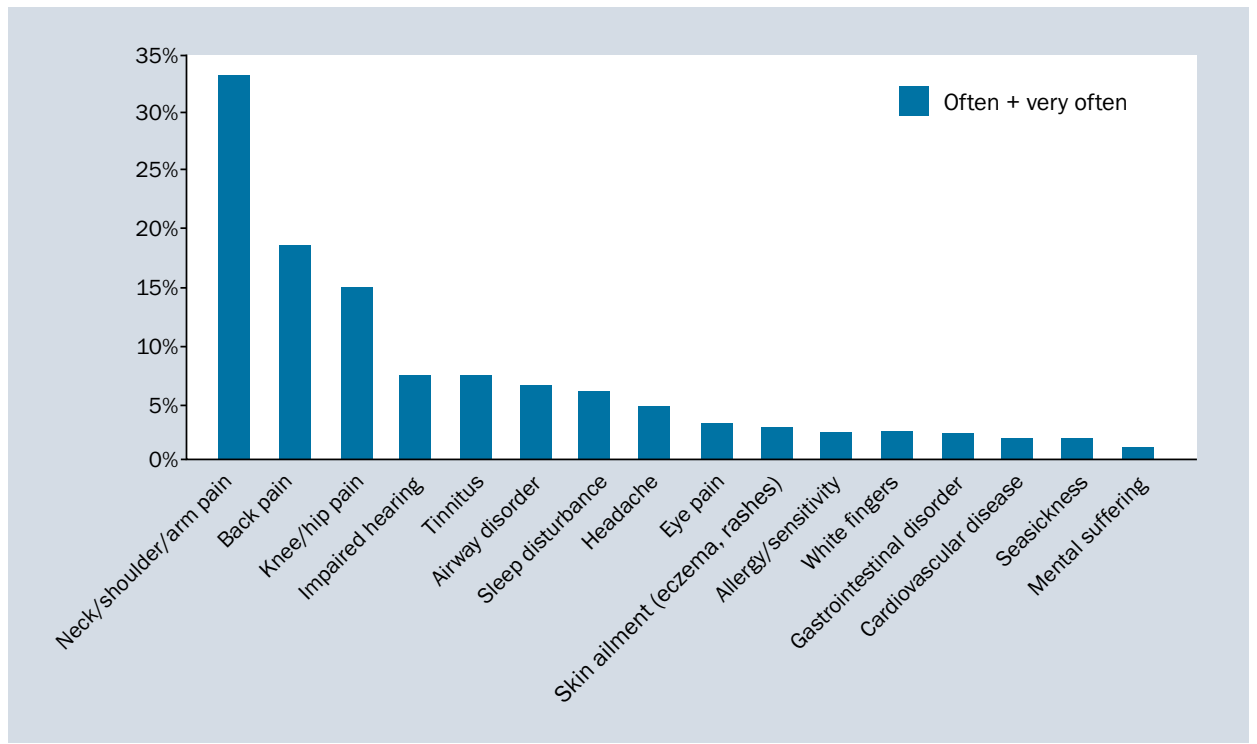

Figure 2. Self-reported health problems among fishers during the previous 12 months $(n=832)$

a 1.6 times higher RR of experiencing musculoskeletal pains, while fishers on purse seine boats have a lower RR of experiencing musculoskeletal pains (0.5) compared to other operations [4]. Notwithstanding these pains, $77 \%$ of the fishers in all the vessel groups reported their own health as being very good or good.

\section{QUESTIONNAIRE}

The questionnaire completed by all crew members of the 5 trawlers $(n=153)$ showed that $54 \%$ and $55 \%$ had experienced stiffness and/or pain in the neck/shoulders and lower back/small of the back during the last 12 months, respectively. In the same period, of those 102 directly engaged in fishing, $57 \%$ and $60 \%$ had experienced such stiffness and/or pain in the neck/shoulders and lower back/small of the back, respectively. Of the fishers who answered in the affirmative to the question about stiffness and/or pain, $62 \%$ believed this was fully or partly due to their work situation; whereas $35 \%$ of the other crew members reported the same.

All the respondents attributed their complaints to repetitive, monotonous movements (39\%), heavy lifting (37\%), work at high speed (22\%) and work with hands at or over shoulder height (22\%). Dividing into subgroups, repetitive, monotonous work was the explanation for complaints among $52 \%$ of the fishers and $14 \%$ among other crew members. This was followed by heavy lifting (46\% fishers 
vs. $20 \%$ other crew members) and working at high speed (30\% fishers vs. $6 \%$ other crew members).

Seventy-five per cent of all the crew members on the 5 trawlers and $77 \%$ of the fishers reported their own health as being very good or good.

\section{DISCUSSION}

Our findings from the registries supported our hypothesis that MSD were the main cause of absence due to sickness. Compared to the control population they suffered significantly more acute incidents due to musculoskeletal diseases and injuries to arms, feet and backs. Even though more than two-thirds of the fishers reported their own health as being very good or good, they reported a high incidence of MSD.

In our study monotonous work operations (61\%), heavy lifting (43\%) and working twisted/bended (42\%) were reported often/very often among occupational fishers in the telephone survey and were often the main reasons for the MSD. The self-reported pain in the neck/shoulders/ /arms was fully or partly explained by their work situation by $93 \%$ of our sample. Our results are supported by other studies of fishers $[6,32,33]$ and similar studies have also shown that perceived workload and musculoskeletal pain are closely linked to the occurrence of MSD [34]. Data from the Danish Working Environment Authority also shows that monotonous work postures and repetitive work increase the risk of developing pain in the musculoskeletal system [35]. Østergaard et al. (2016) [6] found that standing was fishers' most frequent work position, while repetitive hand and finger movements and lumbar twisting and bending were other frequent postures. They also showed that correct lifting techniques are known. However, only about half of the respondents used such techniques at work [33]. Reducing ergonomic exposures associated with work among these occupations is important, regardless of whether they directly cause or contribute to their musculoskeletal symptoms or aggravate existing pathology [5].

The literature regarding physical strain of fishing is sparse [28] but some studies have reported cardiovascular strain of fishers [36-38]. Previous studies based on Norwegian coastal fishing have shown that work on the trawl deck can be characterised as an intermittent activity with average levels of cardiac strain. A newer study of thermophysiological responses and work strain during work on trawl deck [30] showed that workers are periodically exposed to high work strain, manifested as raised core temperature and heart rate when working on the trawl deck. These results show that cardiovascular strain among fishers is moderate to heavy. In our study, repetitive movements, heavy lifting and working at high speed were the most common explanations for MSD. This is in also accordance with Törner et al. (1988) [33], who claimed that symptoms follow a logical pattern according to age, number of years in the fishing industry, type of fishing operation and type of work performed on board, where heavier work-load leads to higher incidence of symptoms/discomfort as well as musculoskeletal problems [33].

Fishing has been reported to be the most hazardous occupation also due to exposure to cold stress and wind [28]. In our study the fishers reported that they often or very often are exposed to unfavourable working conditions such as humid conditions (68\%), strong winds (37\%) and cold environments (40\%). When the data were analysed in terms of "operational groups" the results also showed that coastal fishers are more exposed to climatic, ergonomic, processing (contact with fish/fishmeal, gutting or processing) factors, and are more likely to experience musculoskeletal problems and to take leave of absence from work than fishers in other modes of operation [4]. A Finnish study reported that progressively lower temperatures increase self-reports of musculoskeletal pain [39], and when repetitive work is combined with exposure to cold environments this may also have a negative effect on muscle function and fatigue [20] that may lead to strain injuries and in the long term, to MSD [21]. Several studies have looked at the incidence of work-related MSD arising from cold indoor work, especially in the fish-processing industry [16, 22, 40-44]. Prolonged low-intensity highly repetitive work in a cold environment can mean a higher risk of developing musculoskeletal symptoms among fishers [5, 12, 23].

Although MSD have previously been studied in a wide range of occupational groups, only a few studies have examined this topic among occupational fishers. One strength of our study is its design, which is based on three different methods; National registries and cross-sectional studies including telephone survey and questionnaire. This combination was intended to provide a well-integrated picture of the situation [45]. Another strength of the study is the very large study population of fishers ( $n=25,971$ ) acquired from the registries (SSB), which gives a robust dataset. Data from SSB also included an age- and gender-matched control population ( $n=77,913$ ), where the ratio of three control subjects per study subject strengthen the reliability of the total dataset. The three methods used in this study included different populations of occupational fishers, and the differences between methods in population size, type of boats, time of the study, wording/framing of the questions may affect the answers. Low response rates are the norm in cross-sectional questionnaire studies of fishers, especially when questionnaires are long, and the presence of a healthy worker effect may influence the findings [6]. Instead of using a questionnaire in written form sent by mail, e-mail or online, we employed telephone interviews that were designed to take 10 minutes, which also helps to 
quell subjects' doubts about the time spent on participating. Although we do not have any information about the total numbers of fishers called, in other studies we have found that using a telephone survey the response rate tends to be high (61\%) [46]. In the questionnaire study on board the deep-sea fishing vessels, $70 \%$ of the crew members answered the questionnaire.

\section{CONCLUSIONS}

Findings from the registries, telephone survey and questionnaire survey all confirmed that MSD are common among Norwegian occupational fishers and that the problems are closely linked to their work situation. Even so, $77 \%$ of both the crews of all the vessel groups and the fishers on the 5 selected trawlers reported their own health as being very good or good. Research and regulation in the Norwegian fishing industry has focussed on acute injuries and fatalities. This study has increased our understanding of environmental challenges and MSD during work and shows that preventative measures as well as technological solutions aimed at reducing strain and exposures related to work are necessary to improve the health of occupational fishers.

\section{ACKNOWLEDGEMENTS}

The authors are grateful to the informants who volunteered to participate in the interviews and the questionnaire study. The results presented in this paper form part of the project "Work environment and health in the Norwegian fishing fleet - challenges and health-promoting factors", which is funded by the Research Council of Norway.

\section{CONFLICT OF INTEREST}

The authors have no conflicts of interest to declare.

\section{REFERENCES}

1. Directorate of Fisheries Statistics for fisheries. https://www fiskeridir no/English/Fisheries/Statistics/Fishermen-fishing-vessels.

2. A Høvdanum AS, Jensen OC, Petursdóttir G, et al. A review of fatigue in fishermen: a complicated and underprioritised area of research. Int Marit Health. 2014; 65(3): 166-172, doi: 10.5603/ IMH.2014.0031, indexed in Pubmed: 25471166.

3. Astrand I, Fugelli P, Karlsson CG, et al. Energy output and work stress in coastal fishing. Scand J Clin Lab Invest. 1973; 31(1): 105-113, indexed in Pubmed: 4687770.

4. Sønvisen SA, Thorvaldsen T, Holmen IM, et al. Work environment and health in the fishing fleet: results from a survey amongst Norwegian fishers. Int Marit Health. 2017; 68(4): 203-210, doi: 10.5603/ IMH.2017.0038, indexed in Pubmed: 29297571.

5. Lipscomb HJ, Loomis D, McDonald MA, et al. Musculoskeletal symptoms among commercial fishers in North Carolina. Appl Ergon. 2004; 35(5): 417-426, doi: 10.1016/j.apergo.2004.04.004, indexed in Pubmed: 15246880.

6. Østergaard H, Jepsen JR, Berg-Beckhoff G. The workload of fishermen: a cross sectional survey among Danish commercial fishermen. Int Marit Health. 2016; 67(2): 97-103, doi: 10.5603/ IMH.2016.0019, indexed in Pubmed: 27364175.

7. Ólafsdóttir H, Rafnsson V. Increase in musculoskeletal symptoms of upper limbs among women after introduction of the flow-line in fish-fillet plants. International Journal of Industrial Ergonomics. 1998; 21(1): 69-77, doi: 10.1016/s0169-8141(97)81985-3.

8. Ose SO. Kunnskap om sykefravær, nye norske bidrag. SINTEF rapport. 2010; A14516.

9. Lærum E, Brage S, Ihlebæk C, Johnsen K, Natvig B, Aas E. Et muskel- og skjelettregnskap. Forekomst og kostnader knyttet til skader, sykdommer og plager i muskel- og skjelettsystemet. Universitetssykehus, Oslo 2013.

10. Grinde J. Ondt ofte lider den fiskermand? Helse og arbeidsmiljø i fiskeryrket. Universitetsforlaget, Oslo 1987.

11. Øren A, Thorvaldsen T, Sønvisen S, Holmen I, Sandsund M. Sickness absence and hospitalization among workers on board Norwegian fishing vessels. Accepted for publishing 2019. Journal of Agromedicine.

12. Törner M, Almström C, Karlsson R, et al. Working on a moving surface-a biomechanical analysis of musculo-skeletal load due to ship motions in combination with work. Ergonomics. 1994; 37(2): 345-362, doi: 10.1080/00140139408963651, indexed in Pubmed: 8119265.

13. Fulmer S, Buchholz B. Ergonomic exposure case studies in Massachusetts fishing vessels. Am J Ind Med. 2002; Suppl 2: 10-18, doi: 10.1002/ajim.10086, indexed in Pubmed: 12210677.

14. Hassi J, Raatikka VP, Huurre M. Health-check questionnaire for subjects exposed to cold. Int J Circumpolar Health. 2003; 62(4): 436-443, doi: 10.3402/ijch.v62i4.17587, indexed in Pubmed: 14964769.

15. Mäkinen TM, Hassi J. Health problems in cold work. Ind Health. 2009; 47(3): 207-220, indexed in Pubmed: 19531906.

16. Piedrahita H, Oksa J, Malm C, et al. Health problems related to working in extreme cold conditions indoors. Int J Circumpolar Health. 2008; 67(2-3): 279-287, doi: 10.3402/ijch.v67i2-3.18286, indexed in Pubmed: 18767348.

17. Rintamaki H. Performance and energy expenditure in cold environments. Alaska Med. 2007; 49(2 Suppl): 245-246.

18. Sandsund M, Reinertsen RE, Bjermer L. Self-reported asthma and exercise-induced respiratory symptoms related to environmental conditions in marathon runners and cross-country skiers. Journal of Thermal Biology. 2001; 26(4-5): 441-447, doi: 10.1016/s03064565(01)00058-4.

19. Sandsund M. Exercise performance in cold weather; cardiorespiratory aspects. In: Science and Nordic skiing. Eds. Linnamo V, Komi PV, Müller E. Meyer \& Meyer Sport, UK. ; 2007: 49-57.

20. Oksa J, Ducharme MB, Rintamäki H. Combined effect of repetitive work and cold on muscle function and fatigue. J Appl Physiol (1985). 2002; 92(1): 354-361, doi: 10.1152/jappl.2002.92.1.354, indexed in Pubmed: 11744678.

21. Chiang HC, Chen SS, Yu HS, et al. The occurrence of carpal tunnel syndrome in frozen food factory employees. Gaoxiong Yi Xue Ke Xue Za Zhi. 1990; 6(2): 73-80, indexed in Pubmed: 2352318.

22. Bang BE, Aasmoe L, Aardal L, et al. Feeling cold at work increases the risk of symptoms from muscles, skin, and airways in seafood industry workers. Am J Ind Med. 2005; 47(1): 65-71, doi: 10.1002/ ajim.20109, indexed in Pubmed: 15597355.

23. Aasmoe L, Bang B, Egeness C, et al. Musculoskeletal symptoms among seafood production workers in North Norway. Occup Med (Lond). 2008; 58(1): 64-70, doi: 10.1093/occmed/kqm136, indexed in Pubmed: 18079142.

24. Rafnsdottir GL, Gudmundsdottir ML. New technology and its impact on well-being. Work. 2004; 22(1): 31-39, indexed in Pubmed: 14757904. 
25. Thorvaldsen T, Kaustell K, Mattila T, et al. What works? Results of a Nordic survey on fishers' perceptions of safety measures. Marine Policy. 2018; 95: 95-101, doi: 10.1016/j.marpol.2018.06.022.

26. McGuinness $\mathrm{E}$, Aasjord $\mathrm{H}$, Utne I, et al. Fatalities in the Norwegian fishing fleet 1990-2011. Safety Science. 2013; 57: 335-351, doi: 10.1016/j.ssci.2013.03.009.

27. McGuinness E, Aasjord $\mathrm{H}$, Utne I, et al. Injuries in the commercial fishing fleet of Norway 2000-2011. Safety Science. 2013; 57: 82-99, doi: 10.1016/j.ssci.2013.01.008.

28. Cheung SS, Lee JKW, Oksa J. Thermal stress, human performance, and physical employment standards. Appl Physiol Nutr Metab. 2016; 41(6 Suppl 2): S148-S164, doi: 10.1139/apnm-2015-0518, indexed in Pubmed: 27277564.

29. Bryman A Triangulation 2010. http://www referenceworld com/ sage/socialscience/triangulation pdf (18.05.2012).

30. Høye EU, Sandsund M, Heidelberg CT, et al. Thermophysiological responses and work strain in fishermen on deep-sea fishing vessels. Int Marit Health. 2016; 67(2): 104-111, doi: 10.5603/ IMH.2016.0020, indexed in Pubmed: 27364176.

31. Sandsund M, Høye E, Heidelberg C, et al. Work environment and health in the Norwegian fishing fleet - a field study on board deepsea fishing vessels. Extreme Physiology \& Medicine. 2015; 4(S1), doi: 10.1186/2046-7648-4-s1-a48.

32. Percin F, Akyol O, Davas A, et al. Occupational health of Turkish Aegean small-scale fishermen. Occup Med (Lond). 2012; 62(2): 148-151, doi: 10.1093/occmed/kqr181, indexed in Pubmed: 22113895.

33. Törner M, Blide G, Eriksson $\mathrm{H}$, et al. Musculo-skeletal symptoms as related to working conditions among Swedish professional fisherman. Appl Ergon. 1988; 19(3): 191-201, indexed in Pubmed: 15676660.

34. Kaerlev L, Jensen A, Nielsen PS, et al. Hospital contacts for injuries and musculoskeletal diseases among seamen and fishermen: a population-based cohort study. BMC Musculoskelet Disord. 2008; 9: 8, doi: 10.1186/1471-2474-9-8, indexed in Pubmed: 18215324.

35. Arbejdstilsynet (DK). Arbejdsrelateret muskel- og skeletbesvær. København (Denmark). 2005. https//arbejdstilsynet.dk/da/ regler/at-vejledninger/a/d-3-4-arbejdsrelateret-muskel-og-skeletbesvaer..
36. Rodahl K, Vokac Z, Fugelli P, et al. Circulatory strain, estimated energy output and catecholamine excretion in Norwegian coastal fishermen. Ergonomics. 1974; 17(5): 585-602, doi: 10.1080/00140137408931399, indexed in Pubmed: 4442391.

37. RodahlK,VokacZ. Workstress in Norwegian trawlerfishermen. Ergonomics. 1977; 20(6): 633-642, doi: 10.1080/00140137708931674, indexed in Pubmed: 590249.

38. Rosahl K, Vokac Z. The work physiology of fishing. Psychother Psychosom. 1979; 32(1-4): 52-59, doi: 10.1159/000287372, indexed in Pubmed: 550187.

39. Pienimäki T, Karppinen J, Rintamäki H, et al. Prevalence of cold-related musculoskeletal pain according to self-reported threshold temperature among the Finnish adult population. Eur J Pain. 2014; 18(2): 288-298, doi: 10.1002/j.1532-2149.2013.00368.x, indexed in Pubmed: 23881586.

40. Olafsdóttir H, Rafnsson V. Musculoskeletal symptoms among women currently and formerly working in fish-filleting plants. Int J Occup Environ Health. 2000; 6(1): 44-49, doi: 10.1179/oeh.2000.6.1.44, indexed in Pubmed: 10637536.

41. Pienimäki T. Cold exposure and musculoskeletal disorders and diseases. A review. Int J Circumpolar Health. 2002; 61(2): 173-182, doi: 10.3402/ijch.v61i2.17450, indexed in Pubmed: 12078965.

42. Ohlsson K, Hansson GA, Balogh I, et al. Disorders of the neck and upper limbs in women in the fish processing industry. Occup Environ Med. 1994; 51(12): 826-832, doi: 10.1136/oem.51.12.826, indexed in Pubmed: 7849867.

43. Dovrat E, Katz-Leurer M. Cold exposure and low back pain in store workers in Israel. Am J Ind Med. 2007; 50(8): 626-631, doi: 10.1002/ajim.20488, indexed in Pubmed: 17595006.

44. Sormunen E, Rissanen S, Oksa J, et al. Muscular activity and thermal responses in men and women during repetitive work in cold environments. Ergonomics. 2009; 52(8): 964-976, doi: 10.1080/00140130902767413, indexed in Pubmed: 19629811.

45. Patton MQ. Enhancing the quality and credibility of qualitative analysis. Health Serv Res. 1999; 34(5 Pt 2): 1189-1208, indexed in Pubmed: 10591279.

46. Thorvaldsen T, Sønvisen S, Holmen IM, et al. iskerhelseundersøkelsen. Fisher health survey. Interaction between work, work environment and health among Norwegian fishers. SINTEF Fiskeri og havbruk AS, Trondheim 2016. 